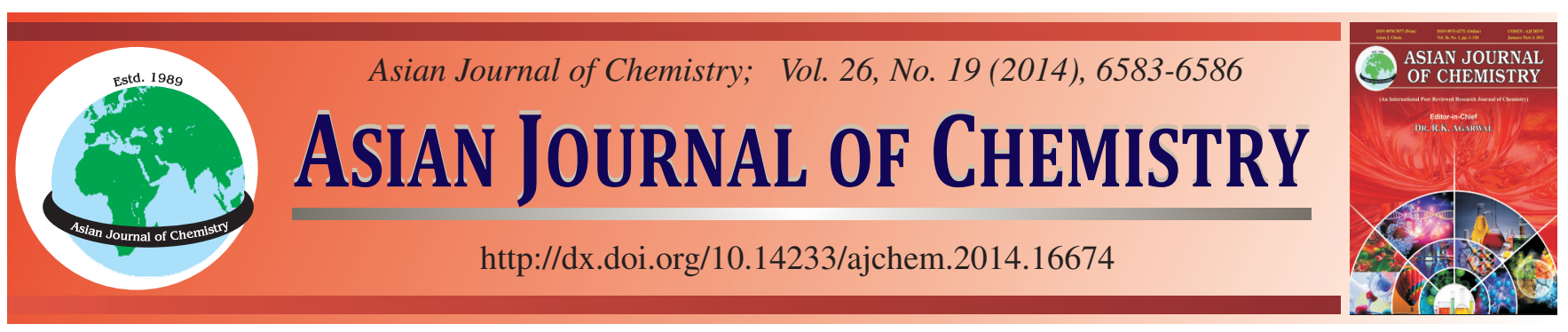

\title{
Simultaneous Determination of Methanol and Ethanol Content in Traditional Chinese Jujube Brandy
}

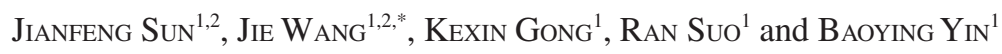

${ }^{1}$ College of Food Science and Technology, Agricultural University of Hebei, Baoding 071000, Hebei Province, P.R. China

${ }^{2}$ Engineering Technology Research Center for Processing of Agricultural Products of Hebei Province, Baoding 071000, P.R. China

*Corresponding author: Fax:+86 312 7528189; Tel: +86 312 7528180; E-mail: wj591010@163.com

Received: 11 November 2013;

Accepted: 22 January 2014;

Published online: 16 September 2014;

AJC-15966

The simultaneous determination of the methanol and ethanol content in traditional Chinese jujube brandy, a simple and rapid method using GC-FID equipped with a semi-polar column (TG-35MS, $30 \mathrm{~m} \times 0.25 \mathrm{~mm} \times 0.50 \mu \mathrm{m}$ ) is presented. Chromatogram showed a retention time of $6.73 \mathrm{~min}$ for methanol and $7.38 \mathrm{~min}$ for ethanol. The linear ranges of the calibration curve for methanol and ethanol were both wide, range from $31.25 \mu \mathrm{g} / 100 \mathrm{~mL}$ to $3.20 \mathrm{~g} / 100 \mathrm{~mL}$ for methanol $\left(\mathrm{R}^{2}=0.9995\right)$ and 1.25 to $80 \% \mathrm{v} / \mathrm{v}$ for ethanol $\left(\mathrm{R}^{2}=0.9969\right)$. Standard addition of methanol and ethanol to traditional Chinese jujube brandy gained excellent recoveries of 101.8 and $101.3 \%$, respectively. With this method, pre-treatment of sample is no longer required and less than 19.10 min is taken for one single analysis from direct injection of original samples to obtaining data. Twenty-four samples of traditional Chinese jujube brandy were detected with this method. The results showed that all samples had a high average ethanol content of $53.4 \pm 8.4 \% \mathrm{v} / \mathrm{v}$, while the average value of methanol content (in $60 \%$ ethanol) was $0.40 \pm 0.09 \mathrm{~g} / 100 \mathrm{~mL}$.

Keywords: Traditional Chinese Jujube Brandy, Methanol, Ethanol, GC-FID.

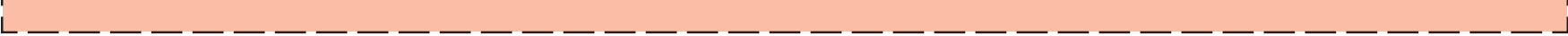

\section{INTRODUCTION}

China is the original country of the jujube, also the largest producing country in the world. The cultivation area of jujube was more than 330,000 hectares in 2011, with annual yield up to 1.1 billion kilograms ${ }^{1}$. China's planting area and yield account for more than $98 \%$ of the world and almost $100 \%$ of the international trade of jujube products comes from China, which plays a significant role in the world's jujube industry ${ }^{2}$. In China, Hebei, Henan, Shandong, Shanxi, Shaanxi and Xinjiang and their total production accounts for more than $90 \%$ of China's total yield ${ }^{1}$. Mainly processed products of jujube in China includes jujube series of drinks including fruit wines, vinegars, fruit and vegetable compound beverages, tea beverages and solid beverages, etc. Traditional Chinese jujube brandy, jujube milk, dried jujube, preserved fruit, etc. ${ }^{3}$.

Jujube brandy is brewed with substandard jujube, which is most produced in family wine distilleries with a process of crushing, wetting, straw mixing, naturally fermentation in tank and distilling by steaming. The obtained traditional Chinese jujube brandy shows a high ethanol content, from 40 to $80 \%$ $\mathrm{v} / \mathrm{v}$ without any blending. The family wine distilleries, whose products are always consumed by themselves, are not certificated by the national production institutes. Traditional
Chinese jujube brandy has yellow color, moderate, pleasant jujube and soft sweet flavor, more important retains the jujube's nutritional value and medicinal value, is a typical health wine which can easily and is fully absorbed by human body ${ }^{3}$.

Traditional Chinese jujube brandy has a history of thousands years in China, but its manufacture and market is restricted in a large extent reason of high methanol content expect a large-scale industrial production. It is well known that methanol is a toxic and harmful substance to human health (when taken orally at $340 \mathrm{mg} / \mathrm{kg}$ of body weight) of whose ingestion or inhalation can cause blindness or death ${ }^{4}$. Newsholme and Leech $^{5}$ reported that oxidized methanol produces lactic acidosis which is a metabolic disease causing an increase of lactic acid in blood. Its symptoms lead to weakness, vomiting and finally coma and death. However, methanol quota is deleted in GB/T $11856-2008^{6}$ which raises wholesome requirement and carries out by GB $2757-2012^{7}$. While GB 2757-2012 $2^{7}$ requires the maximum limit of methanol content is $0.12 \mathrm{~g} / 100 \mathrm{~mL}$ in $60 \% \mathrm{v} / \mathrm{v}$ ethanol (with raw materials of dry sweet potato and substitutes). Therefore, research in methanol formation mechanism and proposing control measures is important and could provide a theoretical basis for large-scale industrial production. 
Subjected to the research, a quick and accurate method to determine the content of methanol and ethanol in traditional Chinese jujube brandy is urgently required. A method for determining methanol in edible wine and volatile compounds of bottled wines using gas chromatography was established by Liu and Díaz, respectively ${ }^{8,9}$. Direct injection of samples into a 30 m CP-Wax 58 CB megapore capillary column with FID has proven useful to determine methanol content in a very short time $(<9 \mathrm{~min})$. The present method is not only quick, but also accurate and reliable when examined in the light of the relative errors and coefficients of variation between repeated analyses and recoveries from standard addition tests ${ }^{10}$. A procedure developed for methanol and ethanol determination in alcoholic samples opens new excite citing possibilities for real applications of vapor phase-FTIR, as compared with the classical liquid phase-FTIR and demonstrates, once again, the capability of the FTIR to provide precise and accurate results in the direct analysis of untreated samples ${ }^{11}$. A simultaneous determination of methanol and ethanol content in fuel ethanol using cyclic voltammetry was introduced ${ }^{12}$ and a methodology for the determination of methanol and ethanol in transformer oil was also reported ${ }^{13}$, however, these methods were not suitable for food.

In order to simultaneous determine methanol and ethanol content in traditional Chinese jujube brandy, a simple and rapid method using GC-FID is presented in this study.

\section{EXPERIMENTAL}

Chromatographic grade solvents (purity above $99.9 \%$ ), such as methanol, isopropyl alcohol, isobutyl alcohol and ethyl acetate were purchased from Tianjin Shield Specialty Chemical Ltd. Co. And analytical grade solvents (purity above 99.5\%), such as ethanol absolute, 1-propanol, N-butanol, 1-pentanol and Isoamyl alcohol were purchased from Tianjin Guangfu Fine Chemical Research Institute Ltd. Co.

Traditional Chinese jujube brandies, including 24 samples in different wine ages, were purchased from several different family wine distilleries located in Wang Lin Kou township, Baoding county, Hebei province. These 24 samples were named as sample 01 to sample 24, respectively. All samples were obtained and preserved in normal temperature warehouse before measured.

GC analysis operational conditions: The analysis of methanol was conducted in an Agilent Technologies 6820 GC (Agilent Technologies, Santa Clara, USA) equipped with a computer integrator software (Petrochemical industry QA/QC Cerity Network Data System, Agilent Technologies, Santa Clara, USA), a 30 m TG-35 MS semi-polar capillary column $(0.25 \mathrm{~mm}$ id, film thickness: $0.50 \mu \mathrm{m}$; Agilent Technologies, Santa Clara, USA) and a flame ionizing detector (Hydrogen: $0.10 \mathrm{Mpa}$ and Air: 0.28 Mpa). Flow rate of carrier gas nitrogen was set at $0.40 \mathrm{Mpa}$. The temperatures at injector port and detector were set at 220 and $230{ }^{\circ} \mathrm{C}$, respectively and split injection (about $2 \mu \mathrm{L}$ for each injection, split ratio $=30: 1$ ) was used. In order to avoid cross contamination between samples, the syringe for injection was completely dried out after rinsing the syringe with $60 \%$ ethanol solution. Oven temperature was controlled with a temperature elevation program during analysis, which was initially set at $40^{\circ} \mathrm{C}$ for 2 min, elevated to $115^{\circ} \mathrm{C}$ at the rate of $5{ }^{\circ} \mathrm{C} / \mathrm{min}$ for $0 \mathrm{~min}$, then elevated to $220{ }^{\circ} \mathrm{C}$ at the rate of $50{ }^{\circ} \mathrm{C} / \mathrm{min}$ and maintained for $0 \mathrm{~min}$. Each sample was injected in triplicate, qualitative test and quantification was based on retention time and external standard method, respectively.

Establishment of standard curve for methanol and ethanol content: The standard solutions for methanol (in 60 $\%$ ethanol) containing a series of concentrations $\left(2-^{10} \mathrm{c}, 2^{-9} \mathrm{c}\right.$, $2^{-8} \mathrm{c}, 2^{-7} \mathrm{c}, 2^{-6} \mathrm{c}, 2^{-5} \mathrm{c}, 2^{-4} \mathrm{c}, 2^{-3} \mathrm{c}, 2^{-2} \mathrm{c}, 2^{-1} \mathrm{c}$ and $\mathrm{c}, \mathrm{c}=3.20 \mathrm{~g} / 100$ $\mathrm{mL}$ ) were analyzed to calculate the response factor. Subsequently, the content of methanol for each sample was determined according to the peak area of methanol from GC analysis mentioned above.

The standard solutions for ethanol (in distilled water) containing a series of concentrations $(1.25,2.5,5,10,20,30$, $40,50,60,70$ and $80, \mathrm{v} / \mathrm{v}, \%)$ were analyzed to calculate the response factor. Subsequently, the content of ethanol for each sample was determined according to the peak area of ethanol from $\mathrm{GC}$ analysis mentioned above.

Recovery test and validation of the method: In order to evaluate the validation of the direct GC method, a range of standard methanol and ethanol concentrations were both determined 5 times. Supplements of 0.05, 0.10 and $0.20 \mathrm{~g} / 100$ $\mathrm{mL}$ methanol standard (in $60 \%$ ethanol) were added to quantified brandy sample, respectively. $1 \mathrm{~mL}$ supplements of 20 , 40 and $60 \%$ ethanol standard $1 \mathrm{~mL}$ were added to $1 \mathrm{~mL}$ quantified brandy sample, respectively. Both $2 \mu \mathrm{L}$ of the mixed samples were subjected to GC analysis mentioned above. Recoveries of the methanol and ethanol were calculated by comparing the original content of methanol and ethanol in the quantified brandy sample and the content with standard addition. Standard deviations of the measured value and relative error of mean were for index of accuracy.

Determination of methanol and ethanol content in traditional Chinese jujube brandy: All samples $2 \mu \mathrm{L}$ for each injection were subjected to GC analysis mentioned above and each sample was injected in triplicate.

\section{RESULTS AND DISCUSSION}

In order to determine the optimum condition for GC analysis of methanol and ethanol, semi-pore capillary columns with film thickness $0.25 \mu \mathrm{m}$ and $0.50 \mu \mathrm{m}$ were compared. Preliminary tests suggested that the column with film thickness $0.50 \mu \mathrm{m}$ (TG-35MS) had the better capability to separate methanol, ethanol and other components in brandy samples. The typical separation profile of known constituents in brandy samples is shown in Fig. 1(A). When compared with other seven authentic compounds, as shown in Fig. 1, the retention time of methanol and ethanol were 6.73 and $7.38 \mathrm{~min}$, respectively, and that of isopropyl alcohol, 1-propanol, ethyl acetate, isobutyl alcohol, N-butanol, isoamyl alcohol and 1-pentanol were $7.80,8.98,10.55,10.64,11.97,14.63$ and $15.94 \mathrm{~min}$, respectively. Consequently, the methanol and ethanol content in a sample could be determined within $19.10 \mathrm{~min}$.

The peak area value of standard methanol and ethanol were determined. As shown in Figs. 2 and 3, the regression between the peak area and the concentration value of methanol 


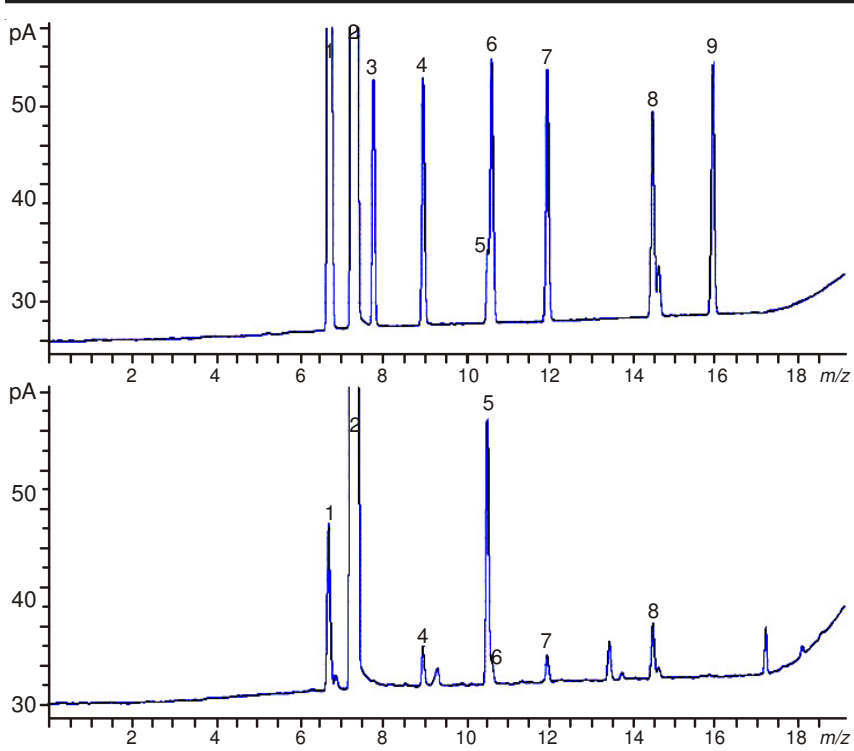

Fig. 1. Gas chromatograms of standard mixture compounds and samples. (A) $1.6 \mathrm{~g} / 100 \mathrm{~mL}$ standard mixture compounds, (B) Traditional Chinese jujube brandy sample compounds (keys of numbers above peaks: 1. methanol, 2. ethanol, 3. isopropyl alcohol, 4. 1-propanol, 5. ethyl acetate, 6. isobutyl alcohol, 7. N-butanol, 8. isoamyl alcohol and 9. 1-pentanol)

and ethanol found for peak area (y) to concentration value (x) were $y=257.27 x+3.5596\left(R^{2}=0.9995\right)$ for methanol and $y$ $=239.19 x+510.32\left(R^{2}=0.9969\right)$ for ethanol, both fitted $\mathrm{a}$ liner relationship well. The linear ranges of the calibration curve for methanol and ethanol were both wide, range from $31.25 \mu \mathrm{g} / 100 \mathrm{~mL}$ to $3.20 \mathrm{~g} / 100 \mathrm{~mL}$ for methanol and 1.25 to $80 \% \mathrm{v} / \mathrm{v}$ for ethanol. The wide linear ranges of methanol and ethanol detection also suggested that this method might be suitable for determination with samples with highly varied methanol and ethanol content, such as traditional Chinese jujube brandy.

Recoveries from a series of standard addition and variations of detection were also used to evaluate the method. Table-1 shows that indiscriminately spiking Chinese jujube brandy with $0.05,0.10$ or $0.20 \mathrm{~g} / 100 \mathrm{~mL}$ of methanol and 20,40 or $60 \%$ of ethanol, they all displayed a good recovery between 101.5 and $102.2 \%$ with a low coefficient of variation between 0.8 and $1.7 \%$ for methanol and between 99.4 and $103.2 \%$ with a low coefficient of variation between 2.3 and $5.2 \%$ for ethanol.

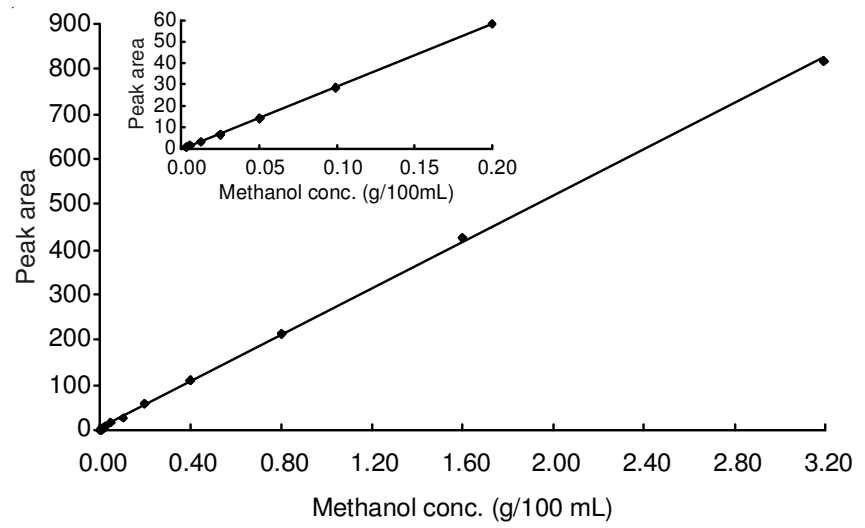

Fig. 2. Calibration curve of methanol

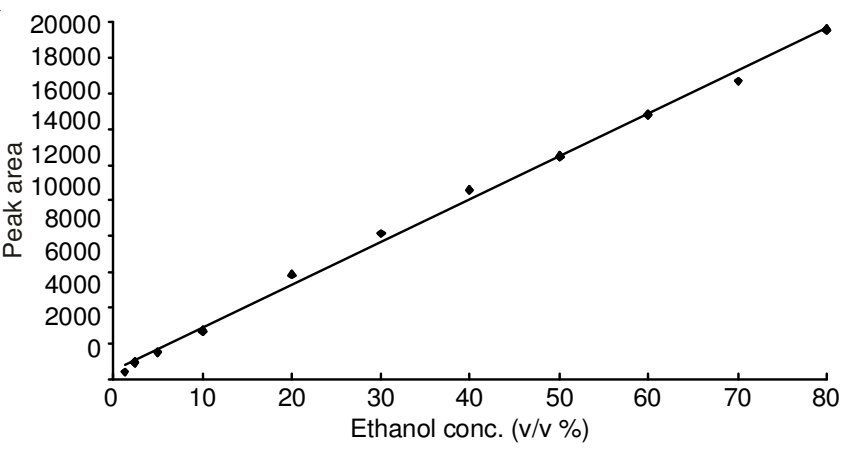

Fig. 3. Calibration curve of ethanol

In addition, varied concentrations of methanol and ethanol standard (from 0.05 to $0.80 \mathrm{~g} / 100 \mathrm{~mL}$ for methanol and from 10 to $80 \%$ v/v for ethanol, respectively) were determined three times in a day. As shown in Table-2, the coefficient of variation of detections made within a day ranged from 2.3 to $7.1 \%$ for methanol and 4.5 to $9.3 \%$ for ethanol, for different concentrations of standard methanol and ethanol, suggesting the method performed with high precision. The relative errors obtained from the determination within a day ranged from -7.8 to $6.3 \%$ for methanol and -8.9 to $7.3 \%$ for ethanol, indicating the method also had high accuracy.

This GC method was also subjected to methanol and ethanol content analysis in several traditional Chinese jujube brandies. Table-3 shows that methanol and ethanol content of Sample 01 to Sample 24. In Sample 01 to Sample 24 where

\section{TABLE-1}

RECOVERIES OF METHANOL AND ETHANOL IN CHINESE JUJUBE BRANDY

\begin{tabular}{|c|c|c|c|c|c|}
\hline \multirow{2}{*}{ Sample } & \multicolumn{3}{|c|}{ Methanol $(\mathrm{g} / 100 \mathrm{~mL}$, in $60 \%$ ethanol $)$} & \multirow{2}{*}{ Mean recovery $(\%)^{\mathrm{c}}$} & \multirow{2}{*}{$\mathrm{CV}(\%)^{\mathrm{d}}$} \\
\hline & $\operatorname{Blank}^{a, b}(A)$ & Added amount (B) & Detected amount $^{\mathrm{b}}(\mathrm{C})$ & & \\
\hline \multirow{10}{*}{$\begin{array}{l}\text { Chinese jujube } \\
\text { brandy }\end{array}$} & \multirow{4}{*}{$0.1995 \pm 0.0132$} & 0.05 & $0.2506 \pm 0.0162$ & 102.2 & 0.8 \\
\hline & & 0.10 & $0.3013 \pm 0.0207$ & 101.8 & 1.7 \\
\hline & & 0.20 & $0.4025 \pm 0.0198$ & 101.5 & 1.5 \\
\hline & & Mean value & & 101.8 & 1.3 \\
\hline & \multicolumn{3}{|c|}{ Ethanol (v/v, \%) } & \multirow{2}{*}{ Mean recovery $(\%)^{\mathrm{e}}$} & \multirow{2}{*}{$\mathrm{CV}(\%)^{\mathrm{d}}$} \\
\hline & $\operatorname{Blank}^{\mathrm{a}, \mathrm{b}}(\mathrm{A})$ & Added amount (B) & Detected amount ${ }^{\mathrm{b}}(\mathrm{C})$ & & \\
\hline & \multirow{4}{*}{$60.0 \pm 2.00$} & 20 & $39.76 \pm 3.43$ & 99.4 & 3.7 \\
\hline & & 40 & $51.60 \pm 2.89$ & 103.2 & 2.3 \\
\hline & & 60 & $60.84 \pm 4.68$ & 101.4 & 5.2 \\
\hline & & Mean value & & 101.3 & 3.4 \\
\hline
\end{tabular}

${ }^{a}$ Original content of methanol or ethanol in $1 \mathrm{~mL}$ quantified brandy sample, ${ }^{\mathrm{b}}$ Data are mean $\pm \mathrm{S}$. D. $(\mathrm{n}=5),{ }^{\mathrm{c}}$ Recovery $(\%)=(\mathrm{C}-\mathrm{A}) / \mathrm{B} \times 100 \%$ ${ }^{\mathrm{d}}$ Coefficient of variation was obtained from quintuplicate tests, ${ }^{\mathrm{e}}$ Recovery $(\%)=\mathrm{C} /(\mathrm{A}+\mathrm{B}) / 2 \times 100 \%$ 
TABLE-2

PRECISION AND ACCURACY ANALYSIS OF METHANOL AND ETHANOL DETECTION AT DIFFERENT CONCENTRATION

\begin{tabular}{|c|c|c|c|c|c|}
\hline \multirow{2}{*}{$\begin{array}{l}\text { Methanol conc. } \\
\text { (g/100 mL) }\end{array}$} & \multicolumn{2}{|c|}{ Within a day ${ }^{a}$} & \multirow{2}{*}{$\begin{array}{l}\text { Ethanol conc. } \\
\qquad(\mathrm{v} / \mathrm{v}, \%)\end{array}$} & \multicolumn{2}{|c|}{ Within a day ${ }^{\mathrm{a}}$} \\
\hline & Measured $^{\text {b }}$ & Accuracy $^{c}$ & & Measured $^{\mathrm{b}}$ & Accuracy $^{c}$ \\
\hline 0.05 & $0.0461 \pm 0.0043$ & -7.8 & 10 & $10.69 \pm 0.96$ & 6.9 \\
\hline 0.10 & $0.1063 \pm 0.0061$ & 6.3 & 20 & $21.46 \pm 1.34$ & 7.3 \\
\hline 0.20 & $0.2108 \pm 0.0094$ & 5.4 & 40 & $37.40 \pm 3.27$ & -6.5 \\
\hline 0.40 & $0.3804 \pm 0.0160$ & -4.9 & 60 & $62.94 \pm 5.39$ & 4.9 \\
\hline 0.80 & $0.7752 \pm 0.0214$ & -3.1 & 80 & $72.88 \pm 9.32$ & -8.9 \\
\hline
\end{tabular}

${ }^{a}$ Repeat injection for three times in the same day $(n=3),{ }^{b}$ Measured is methanol or ethanol content test value, the data of recovery are mean \pm S. D. $(n=3),{ }^{c}$ Accuracy is indicated with the results of relative error $(\%)$ of individual detection to the mean value of detection.

\begin{tabular}{|c|c|c|}
\hline \multicolumn{3}{|c|}{$\begin{array}{c}\text { TABLE-3 } \\
\text { METHANOL AND ETHANOL CONTENT } \\
\text { DETECTED IN SAMPLE } 01 \text { TO SAMPLE } 24\end{array}$} \\
\hline Sample Name & $\begin{array}{c}\text { Ethanol conc. } \\
(\mathrm{v} / \mathrm{v}, \%)^{\mathrm{a}}\end{array}$ & $\begin{array}{l}\text { Methanol conc. } \\
(\mathrm{g} / 100 \mathrm{~mL})^{\mathrm{b}}\end{array}$ \\
\hline Sample 01 & 52.12 .2 & $0.43 \pm 0.02$ \\
\hline Sample 02 & $45.2 \pm 1.9$ & $0.19 \pm 0.01$ \\
\hline Sample 03 & $44.7 \pm 1.9$ & $0.50 \pm 0.03$ \\
\hline Sample 04 & $43.9 \pm 1.9$ & $0.29 \pm 0.02$ \\
\hline Sample 05 & $56.5 \pm 2.4$ & $0.48 \pm 0.03$ \\
\hline Sample 06 & $47.9 \pm 2.1$ & $0.40 \pm 0.02$ \\
\hline Sample 07 & $49.8 \pm 2.1$ & $0.40 \pm 0.01$ \\
\hline Sample 08 & $59.4 \pm 2.6$ & $0.46 \pm 0.02$ \\
\hline Sample 09 & $45.9 \pm 2.0$ & $0.40 \pm 0.01$ \\
\hline Sample 10 & $46.8 \pm 2.0$ & $0.39 \pm 0.02$ \\
\hline Sample 11 & $76.7 \pm 3.3$ & $0.31 \pm 0.02$ \\
\hline Sample 12 & $48.7 \pm 2.1$ & $0.48 \pm 0.03$ \\
\hline Sample 13 & $50.9 \pm 2.2$ & $0.49 \pm 0.03$ \\
\hline Sample 14 & $65.0 \pm 2.8$ & $0.38 \pm 0.02$ \\
\hline Sample 15 & $56.1 \pm 2.4$ & $0.42 \pm 0.02$ \\
\hline Sample 16 & $49.8 \pm 2.1$ & $0.17 \pm 0.01$ \\
\hline Sample 17 & $63.4 \pm 2.7$ & $0.50 \pm 0.03$ \\
\hline Sample 18 & $53.4 \pm 2.3$ & $0.41 \pm 0.02$ \\
\hline Sample 19 & $57.7 \pm 2.5$ & $0.35 \pm 0.02$ \\
\hline Sample 20 & $67.7 \pm 2.9$ & $0.40 \pm 0.02$ \\
\hline Sample 21 & $42.8 \pm 1.8$ & $0.49 \pm 0.03$ \\
\hline Sample 22 & $47.0 \pm 2.0$ & $0.46 \pm 0.02$ \\
\hline Sample 23 & $54.0 \pm 2.3$ & $0.48 \pm 0.03$ \\
\hline Sample 24 & $55.7 \pm 2.4$ & $0.42 \pm 0.02$ \\
\hline Average Value $^{\mathrm{c}}$ & $51.3 \pm 8.2$ & $0.40 \pm 0.09$ \\
\hline \multicolumn{3}{|c|}{$\begin{array}{l}{ }^{\mathrm{a}} \text { The data of Ethanol conc. are mean } \pm \text { S. D. }(\mathrm{n}=3),{ }^{\mathrm{b}} \text { The Methanol } \\
\text { concentration value was the conversion into Ethanol concentration } 60 \\
\%, \mathrm{v} / \mathrm{v},{ }^{\mathrm{c}} \text { The data of Average Value according Sample } 01 \text { to Sample } 24 \\
\text { are mean } \pm \text { S. D. }(\mathrm{n}=24)\end{array}$} \\
\hline
\end{tabular}

ethanol content ranged from $42.8 \pm 1.8 \%$ (mean \pm S. D., $\mathrm{n}=$ 3) to $76.7 \pm 3.3 \%($ mean \pm S. D., $n=3)$ and average ethanol content was $53.4 \pm 8.4 \%($ mean $\pm \mathrm{S}$. $\mathrm{D} ., \mathrm{n}=24)$. Therefore, in general Traditional Chinese Jujube Brandy had a very high content of alcohol. While methanol content (in $60 \%$ ethanol) ranged from $0.17 \pm 0.01 \mathrm{~g} / 100 \mathrm{~mL}($ mean $\pm \mathrm{S}$. D., $\mathrm{n}=3$ ) to $0.50 \pm 0.03 \mathrm{~g} / 100 \mathrm{~mL}$ (mean $\pm \mathrm{S}$. D., $\mathrm{n}=3$ ) with the average value $0.40 \pm 0.09 \mathrm{~g} / 100 \mathrm{~mL}$ (mean $\pm \mathrm{S}$. D., $\mathrm{n}=24$ ). According to GB $2757-2012^{8}$ distilled spirits and liquor preparation hygiene standards (SAC), the average methanol content (in $60 \%$ ethanol) in traditional Chinese jujube brandy is extremely high, even exceeding the maximum legal limits more than 2.3 times. Therefore, studying on the formation mechanism of methanol and proposing control measures is urgent and significant.

\section{Conclusion}

A novel method was setup which could determine methanol and ethanol content simultaneous in traditional Chinese jujube brandy by GC-FID. Using this method to detect the samples, it is found that the traditional Chinese jujube brandy had a high ethanol content of $53.4 \pm 8.4 \% \mathrm{v} / \mathrm{v}$ and $0.40 \pm 0.09$ $\mathrm{g} / 100 \mathrm{~mL}$ (in $60 \%$ ethanol) of methanol. Besides, both of ethanol and methanol contents in all samples exceeded the legal limits of GB 2757-20128. The average value even exceeded the maximum legal limits more than 2.3 times.

\section{ACKNOWLEDGEMENTS}

This study was supported by National Natural Science Foundation of China (NSFC) \# 31171725/2011 and 31371815/ 2013. NSFC had no further role in the study design; in the collection, analysis and interpretation of data; in writing; nor in the decision to submit the manuscript for publication.

\section{REFERENCES}

1. W. Song and B.H. Zhao, J. Anhui Agric. Sci., 39, 21475 (2011).

2. P. Liu, J. Zhou, L. Da and S. Yancheva, J. Mt. Agric. Balkans, 8, 872 (2005).

3. Z.X. Lv, P. Liu and X.Y. Wang, Farm Prod. Process, 12, 58 (2011).

4. B. Gnekow and C.S. Ough, Am. J. Enol. Vitic., 27, 1 (1976).

5. E.A. Nessholme and A.R. Leech, Bioquimica Medica, Interamericana and McGraw Hill, pp. 412-414 (1986).

6. SAC, GB/T 11856-2008: Brandy, Standardization Administration of the People's Republic of China, Beijing, China (2008).

7. SAC, GB 2757-2012: China National Food Safety Standard-Distilled Wines and its Mixed Wines, Standardization Administration of the People's Republic of China, Beijing, China (2012).

8. X.P. Liu, H.A. Liu, C. Zhang and L. Zhang, Sci. Technol., 5, 76 (2001).

9. C. Díaz, J.E. Conde, J.J. Méndez and J.P. Pérez Trujillo, Food Chem., 81, 447 (2003).

10. M.L. Wang, J.T. Wang and Y.M. Choong, J. Food Compos. Anal., 17, 187 (2004)

11. J.M. Garrigues, A. Pérez-Ponce, S. Garrigues and M. de la Guardia, Vib. Spectrosc., 15, 219 (1997).

12. P.F. Pereira, R.M.F. Sousa, R.A.A. Munoz and E.M. Richter, Fuel, 103, 725 (2013).

13. J. Jalbert, S. Duchesne, E. Rodriguez-Celis, P. Tétreault and P. Collin, J. Chromatogr. A, 1256, 240 (2012). 